\author{
Jurnal E-KOMTEK (Elektro-Komputer-Teknik) \\ Vol. 4 No. 1 (2020) pp. 91-99 \\ https://jurnal.politeknik-kebumen.ac.id/index.php/E-KOMTEK \\ p-ISSN : 2580-3719 e-ISSN : 2622-3066
}

\title{
Perawatan Alat Peraga Elektropneumatik Model Suitcase Portable
}

\author{
Yohanes Sinung Nugroho ${ }^{1}$, Adhan Efendi' ${ }^{2}$, Muhammad Fahmi ${ }^{3}$ \\ 1Jurusan Teknik Aeronautika, Politeknik Negeri Bandung, Bandung Barat, Indonesia, 40559 \\ 2,3Jurusan Pemeliharaan Mesin, Politeknik Negeri Subang, Subang, Indonesia, 41211 \\ *E-mail : sinung.polban@gmail.com \\ Doi : https://doi.org/10.37339/e-komtek.v4i1.218
}

Diterbitkan oleh Politeknik Dharma Patria Kebumen

\section{Info Artikel}

Diterima :

28-04-2020

Diperbaiki :

05-06-2020

Disetujui :

17-06-2020

\begin{abstract}
ABSTRAK
Politeknik Negeri Subang merupakan lembaga pendidikan vokasi baru yang dibangun di Kabupaten Subang dan memiliki potensi menjadi salah satu sekolah vokasi unggulan sesuai dengan bidang keahliannya. Penelitian ini bertujuan untuk membuat petunjuk pengoperasian dan perawatan alat peraga elektropneumatik yang telah dibuat pada penelian sebelumnya. Jenis penelitian ini merupakan penelitian pengembangan. Pengambilan data menggunakan observasi dan dokumentasi. Data yang diambi lalu dianalisis menggunakan analisis deskriptif kualitatif. Hasil penelitian menunjukan bahwa: 1) Petunjuk pengoperasian dari alat peraga elektropneumatik ini memilki tata cara dalam pengoperasiannya; 2) Rencana perawatan alat peraga elektropneumatik terdiri atas; pemeriksaan kompresor, pelumasan bearing motor listrik, pemeriksaan selang pada silinder, pemeriksaan selang pada selenoid valve, pemeriksaan selang air filter, membersihkan filter dalam tabung, pemeriksaan semua aliran, selenoid valve, limit switch, relay dan tombol dudukan banana plug.

Kata Kunci: Alat Peraga Elektropneumatik; Pengoperasian; Perawatan
\end{abstract}

\begin{abstract}
Subang State Polytechnic is a new vocational education institution built in Subang Regency and has the potential to become one of the leading vocational schools in accordance with their fields of expertise. This study aims to make the operating instructions and maintenance of electropneatic teaching aids that have been made in the previous study. This type of research is development research. Retrieval of data using observation and documentation. Data collected was analyzed using qualitative descriptive analysis. The results of the study show that: 1) The operating instructions of this electropneatic teaching aid have procedures for their operation; 2) Maintenance plan for electropneatic props consists of; compressor check, lubrication of electric motor bearings, check hose on cylinders, check hose on selenoid valve, check filter water hose, clean filters in tubes, check all flow, selenoid valve, limit switch, relay and banana plug mounting button.
\end{abstract}

Keywords: Electropneatic Trainer; Operation; Maintenance

\begin{tabular}{|c|c|}
\hline Alamat Korespondensi & Jl. Letnan Jenderal Suprapto No.73 Kebumen, Jawa Tengah, Indonesia 55431 \\
\hline (c) & $\begin{array}{l}\text { This work is licensed under a Creative Commons Attribution-NonCommercial } 4.0 \\
\text { International License. }\end{array}$ \\
\hline
\end{tabular}




\section{PENDAHULUAN}

Politeknik Negeri Subang adalah salah satu perguruan tinggi negeri yang ada di wilayah Kabupaten Subang. Terdapat jurusan teknik perawatan dan perbaikan mesin, didalam jurusan tersebut terdapat mata kuliah praktek pneumatik dan hidrolik. Mata kuliah praktik pneumatik dan hidrolik sangat penting untuk dipelajari karena merupakan salah satu mata kuliah wajib di Politeknik Negeri Subang. Namun permasalahan yang didapat dalam melaksanakan praktik pneumatik dan hidrolik yaitu kurangnya pemahaman mahasiswa dalam mata kuliah praktik pneumatik dan hidrolik tersebut dikarenakan terkendala peralatan yang kurang jumlahnya dibandingkan dengan jumlah mahasiswa.

Alat praktik pneumatik dan hidrolik yang digunakan di Politeknik Negeri Subang merupakan mesin industri, ukuran dari mesin tersebut cukup besar dan alat dan bahan nya pun cukup banyak, membuat mahasiswa dapat kebingungan karena harus mempelajari banyak komponen utama dan komponen pendukung. Rahdiyanta dkk [1] dalam bidang vokasi peran pendidikan dan fasilitas akan mempengraruhi prestasi dan kompetensi lulusan tersebut. Sofyan dan Efendi [2] kompetensi pneumatik dan elektropneumatik merupakan syarat penting dalam penerapan sistem kontrol otomatis.

Sistem pneumatik merupakan suatu sistem kerja yang menggunakan udara terkompresi sebagai media kontrol dan media kerja. Jika dilihat dari karakteristik bahan bakunya, sistem pneumatik mempunyai keunggulan seperti bahan baku yang melimpah yaitu udara, mudah digunakan, mempunyai kecepatan yang relatif tinggi, aman terhadap beban berlebih dan tidak mudah terpengaruh oleh perubahan suhu. Ditambahkan oleh Banesz [3] diperlukan alat peraga pneumatik untuk menambah pengetahuan siswa mengenai kompetensi pneumatik yang kerap diterapkan di dunia industri. Hasil penelitian Barber [4] bahwa penggunaan alat peraga pneumatik dapat meningkatkan prestasi peserta didik di bidang vokasi. Diperlukan juga pembuatan desain dan proses manufaktur untuk membuat alat peraga yang sesuai dengan standar [5].

Menurut Priyonggo dan Hariyanto [6] simulasi alat pneumatic akan sangat menunjang kompetensi peserta didik agar lebih optimal. Alat peraga berguna sebagi alat bantu untuk mempermudah dosen atau guru dalam menyampaikan materi pembelajarannya. Dengan adanya media belajar mahasiswa dapat memahami dengan mudah karena penyampaian materi dikemas secara menarik [7]. Hal utama lainnya menurut Prabowo [8] perlu dilakukan perawatan alat agar 
kondisi alat tetap dalam kondisi baik siap digunakan. Ditambahkan oleh Basuki [9] peserta didik bidang vokasi belum banyak mempunyai kemampuan mengenai kontrol otomatis yang diterapkan pada pneumatik.

\section{MATERIAL DAN METODE}

Jenis penelitian ini merupakan penelitian pengembangan. Metode pengambilan data menggunakan observasi dan dokumentasi. Dokumentasi diharapkan menjadi pelengkap dari penggunaan metode observasi dan wawancara dalam penelitian kualitatif. Data yang diambil lalu dianalisis menggunakan analisis deskriptif kualitatif. Deskriptif kualitatif adalah sebuah metode analisis yang digunakan peneliti untuk menemukan pengetahuan atau teori terhadap penelitian pada suatu waktu tertentu. Variabel terikat dalam penelitian ini adalah petunjuk pengoperasian dan perawatan pada alat peraga elektropneumatik.

Tahapan penelitian dimulai dengan peneliti melakukan identifikasi alat peraga elektropneumatik mulai dari pengecekan air filter, selang, nepple, dan kompresor. Setelah mengidentifikasi peneliti membuat standar operasional prosedur (SOP) penggunaan alat serta pembuatan jadwal komponen apa saja yang akan dilakukan perawatan, dan selanjutnya dilakukan validasi ahli untuk melihat kelayakan SOP dan jadwal perawatan. Apabila tidak layak, akan dilakukan revisi untuk memperbaiki hasil tersebut.

\section{HASIL DAN PEMBAHASAN}

\subsection{Pembahasan}

\section{a. Identifikasi dan SOP (Standar Operasional Prosedur)}

Peneliti melakukan pemeriksaaan awal terhadap alat peraga elektropenumatik. Pengecekan air filter, selang, nepple, dan kompresor bertujuan agar peneliti memiliki dasar komponen apa saja yang membutuhkan perawatan. Setelah mencatat semua komponen tersebut, peneliti melakukan pemeriksaan semua komponen seperti kompresor dan alat peraga dalam keadaan siap beroperasi, lalu sebelum beroperasi, aktifkan tombol emergency stop terlebih dahulu agar menjaga komponen saat terjadinya trouble pada saat pengoperasian sedang berjalan. Berikut ini langkah-langkah pemeriksaan alat peraga elektropenumatik :

1) Pemeriksaan komponen dan pengaktifan tombol emergency sebelum alat beroperasi disajikan pada Gambar 1. 

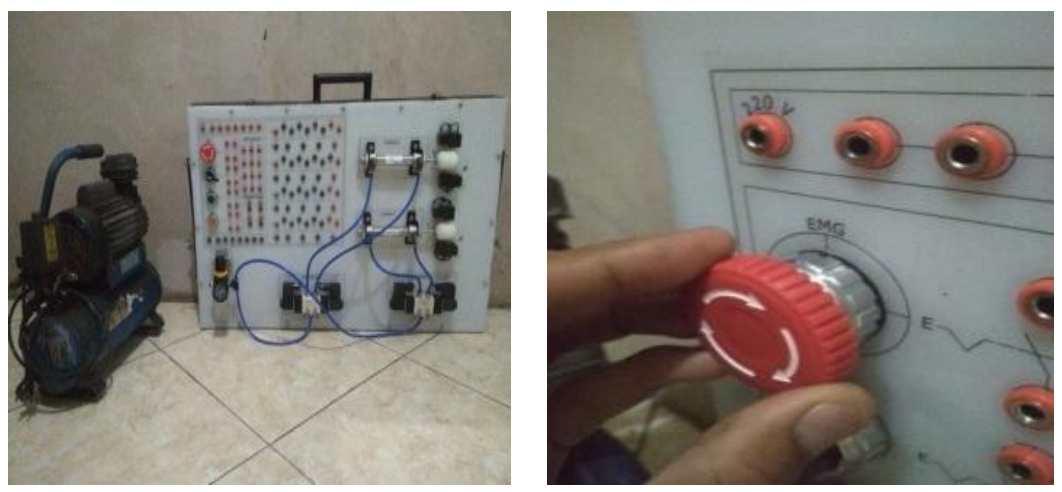

Gambar 1. Pemeriksaan Komponen dan Pengaktifan Tombol Emergency

Bentuk alat peraga elektropneumatik yang portable dengan model koper tidak memiliki kesamaan dengan penelitian sebelumnya. Budi [9] berpendapat bahwa pembuatan trainer kit pneumatik yang khas, membuat peserta didik lebih mudah memahami materi yang disampaikan.

2) Menyalakan kompresor sebagai sumber udara dan membuka katup pada kompresor. Menyalakan kompresor disajikan pada Gambar 2.

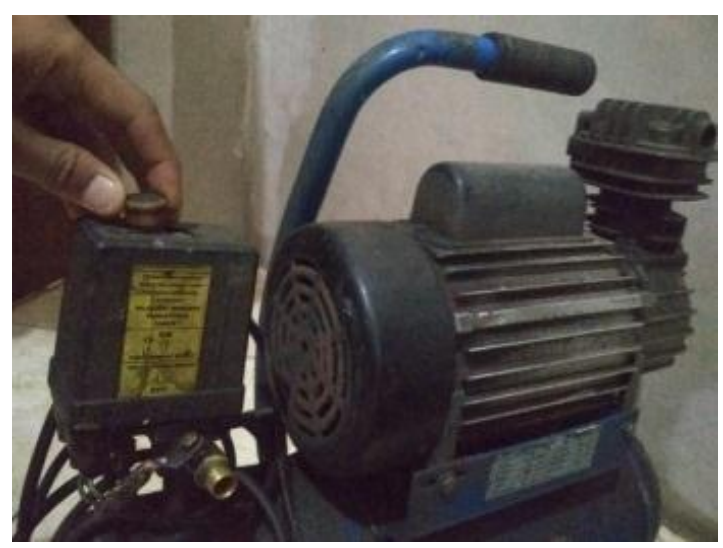

Gambar 2. Menyalakan Kompresor.

3) Kemudian tekan tombol push button on agar menunjukan gerakan pada silinder. Menekan tombol push button on disajikan pada Gambar 3.

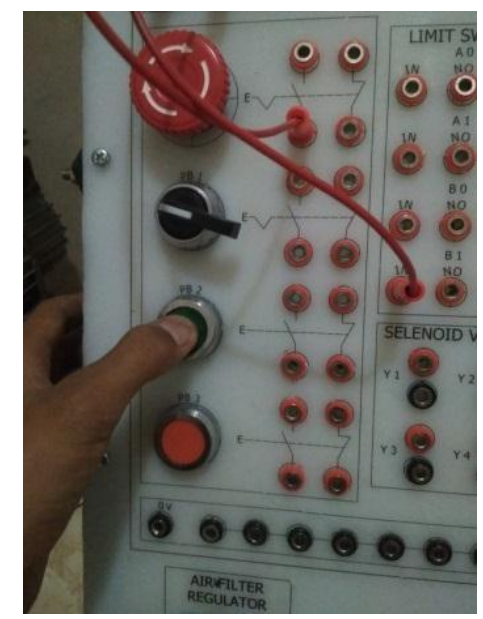

Gambar 3. Menekan Tombol Push Button On. 
4) Sesudah beroperasi, tekan tombol emergency stop untuk mematikan semua komponen yang terhubung dengan arus listrik. Tutup katup pada bagian kompresor dan matikan kompresor. Menekan tombol emergency stop dan menutup tutup katup kompresor disajikan pada Gambar 4.
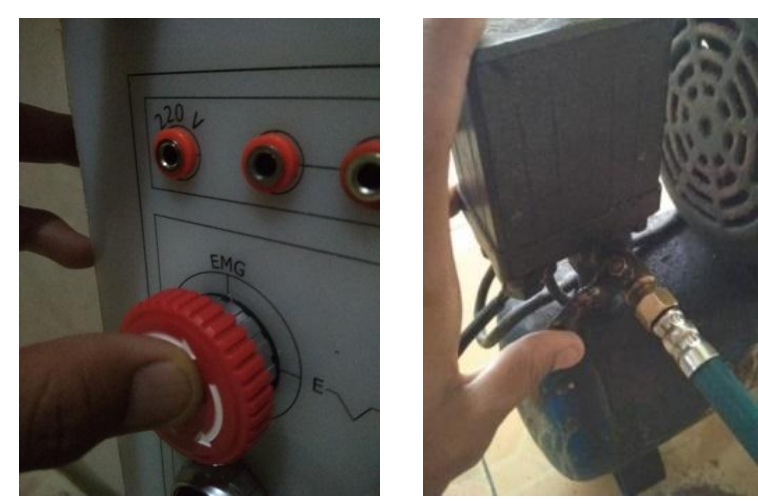

Gambar 4. Menekan Tombol Emergency Stop dan Menutup Tutup Katup Kompresor

\section{b. Rencana Perawatan}

Pembuatan jadwal perawatan dimaksudkan untuk menjaga kondisi alat peraga agar dalam kondisi siap pakai. Setelah komponen dan jadwal selesai kemudian dilakukan validasi oleh ahli. Bapak Aditya Nugraha M.S selaku dosen pneumatik di Politeknik Negeri Subang. Berdasarkan validasi ahli dinyatakan bahwa prosedur dan rencana jadwal perawatan alat peraga elektropneumatik sudah sesuai dan dapat diterapkan. Berikut hasil tabel jadwal perawatan yang telah melalui tahap validasi. Adapun langkah perawatan alat peraga pneumatik tersebut, adalah sebagai berikut:

1) Pemeriksaan pada kompresor, lepaskan selang secara manual pada katup kompresor dan pemeriksaan kebocoran, membersihkan kotoran/ debu. Melakukan pelumasan bearing pada motor listrik. Ditambahkan oleh [10] rencana perawatan mesin diharapkan mampu menjaga kondisi alat agar tetap dalam kondisi siap kerja. Pemeriksanaan Kebocoran pada- Kompresor dan pelumasan bearing disajikan pada Gambar 5.
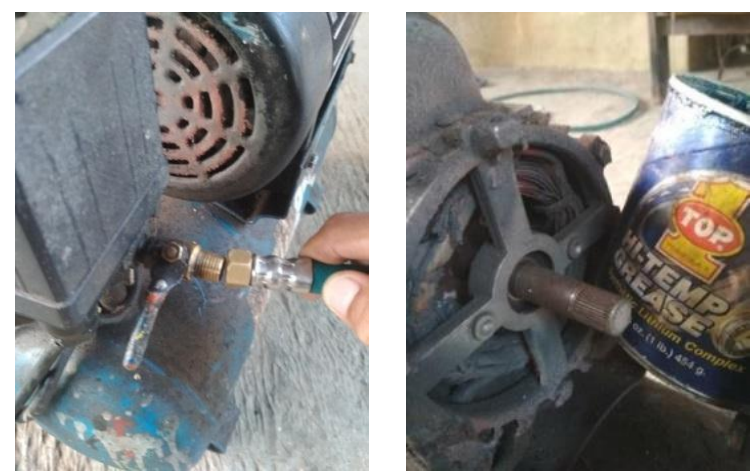

Gambar 5. Pemeriksanaan Kebocoran pada- Kompresor dan pelumasan bearing 
2) Pemeriksaan kebocoran selang pada silinder dengan membersihkan kotoran/debu. Pemeriksaan kebocoran selang pada solenoid valve dengan membersihkan kotoran/debu. Pemeriksanaan silinder dan pemeriksaan katup solenoid disajikan pada Gambar 6.
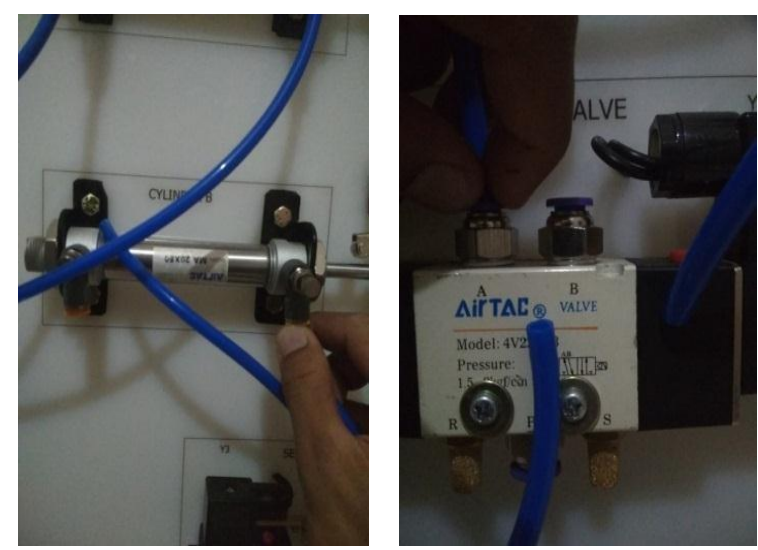

Gambar 6. Pemeriksanaan Silinder dan Pemeriksaan Katup Selenoid

3) Pemeriksaan kebocoran pada selang air filter dan membersihkan filter dalam tabung. Pemeriksanaan air filter dan membersihkan filter disajikan pada Gambar 7.
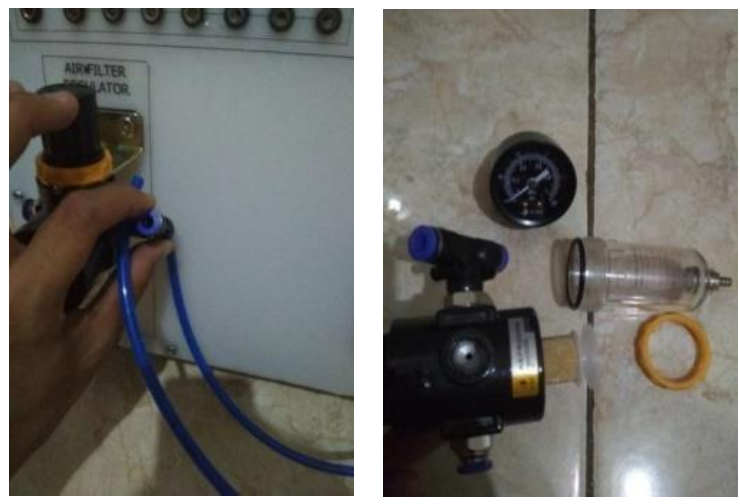

Gambar 7. Pemeriksanaan Air Filter dan Membersihkan Filter

4) Pemeriksaan semua aliran seperti solenoid valve, limit switch, tombol ke dudukan banana plug, menggunakan avo meter. Pengecekan aliran relai disajikan pada Gambar 8.

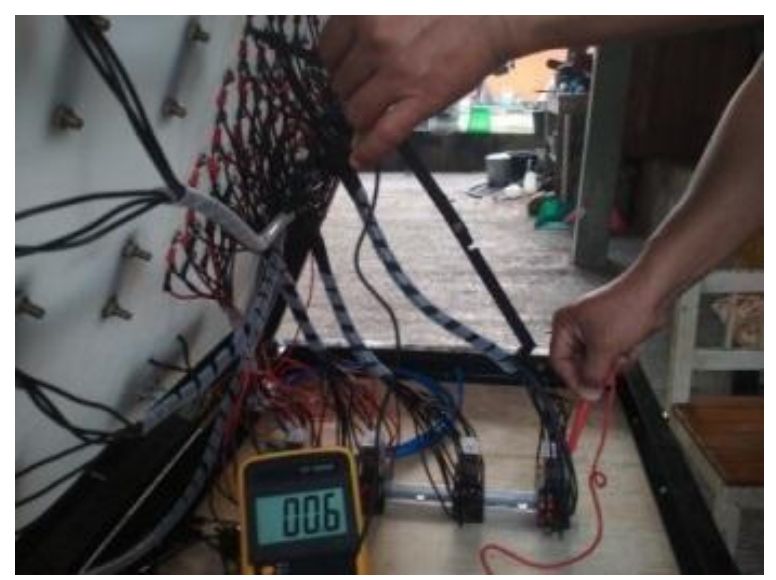

Gambar 8. Pengecekan Aliran Relai 
Pengecekan aliran tombol disajikan pada Gambar 9.

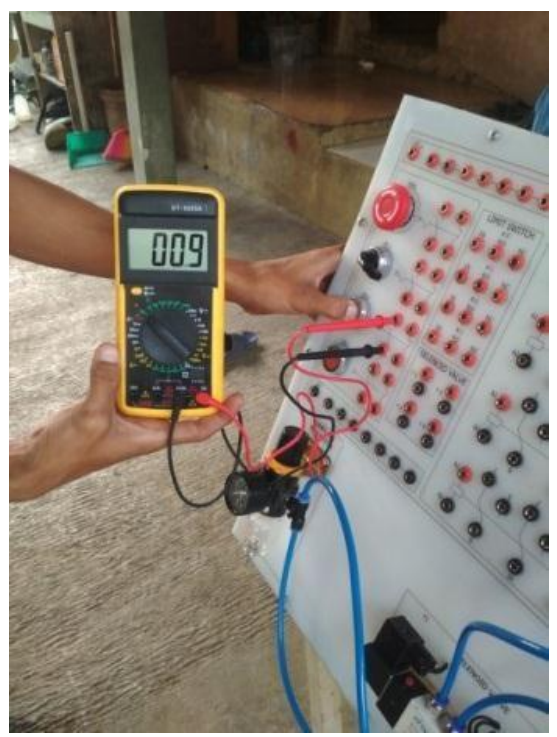

Gambar 9. Pengecekan Aliran Tombol

Pengecekan aliran limit switch disajikan pada Gambar 10.

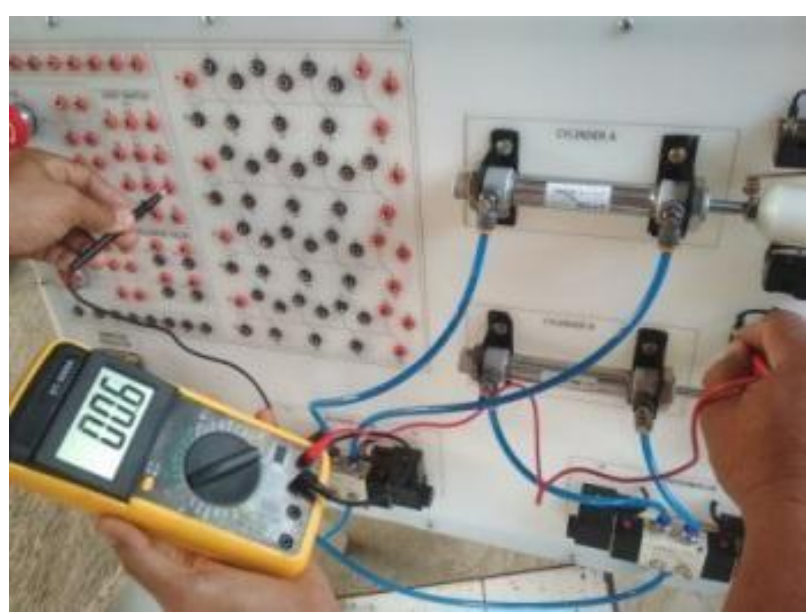

Gambar 10. Pengecekan Aliran Limit Switch

Pengecekan aliran selenoid valve disajikan pada Gambar 11.

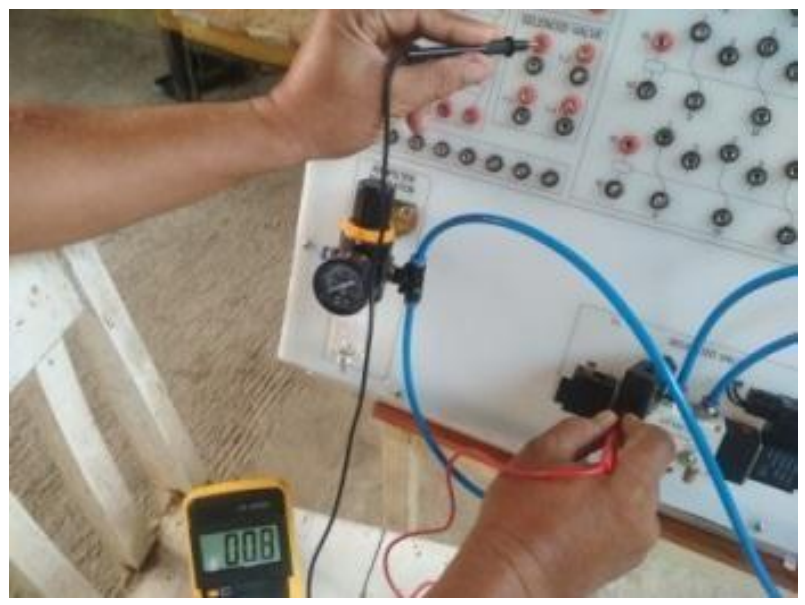

Gambar 11. Pengecekan Aliran Selenoid Valve 


\subsection{Hasil}

Hasil penelitian didapatkan SOP (Standar Operasional Prosedur) sebagai petunjuk pengoperasian alat peraga elektropneumatik. Rencana perawatan alat peraga elektropneumatik terdiri atas; pemeriksaan kompresor, pelumasan bearing motor listrik, pemeriksaan selang pada silinder, pemeriksaan selang pada selenoid valve, pemeriksaan selang air filter, membersihkan filter dalam tabung, pemeriksaan semua aliran, selenoid valve, limit switch, relay dan tombol dudukan banana plug. SOP (Standar Operasional Prosedur) dan rencana perawatan trainer pneumatik disajikan pada Tabel 1.

Tabel 1. SOP (Standar Operasional Prosedur) dan Rencana Perawatan Trainer Pneumatik

\begin{tabular}{|c|c|c|c|c|c|c|}
\hline \multicolumn{7}{|c|}{ SOP dan Rencana Perawatan Trainer Pneumatik } \\
\hline \multirow[b]{2}{*}{ No } & \multirow{2}{*}{$\begin{array}{c}\text { Nama } \\
\text { Komponen }\end{array}$} & \multicolumn{2}{|c|}{ Jenis Perawatan } & \multirow{2}{*}{ Cara Pemeriksaan } & \multirow{2}{*}{ Cara Perawatan } & \multirow{2}{*}{$\begin{array}{l}\text { Jumlah Jam } \\
\text { Perawatan }\end{array}$} \\
\hline & & I $\mathrm{S}$ & $\begin{array}{ll}\mathrm{M} & 0 \\
\end{array}$ & & & \\
\hline 1. & Kompresor & $\sqrt{ }$ & & $\begin{array}{l}\text { Lakukan inspeksi } \\
\text { sistem secara } \\
\text { menyeluruh dari } \\
\text { kebocoran. }\end{array}$ & $\begin{array}{l}\text { Tekang fitting lepaskan } \\
\text { selang dan bersihkan dari } \\
\text { kotoran/debu, sesudah } \\
\text { dibersihkan selang dan } \\
\text { fitting kembali dipasang } \\
\text { dengan menekan fitting lalu } \\
\text { selang masukan kedalam } \\
\text { fitting }\end{array}$ & 10 menit \\
\hline \multirow[t]{2}{*}{2} & $\begin{array}{l}\text { Solenoid } \\
\text { Valve }\end{array}$ & $\sqrt{ }$ & & $\begin{array}{l}\text { Lakukan infeksi } \\
\text { kebocoran }\end{array}$ & $\begin{array}{l}\text { Tekan fitting lalu buka } \\
\text { seluruh selang bagian } \\
\text { solenoid dan bersihkan dari } \\
\text { kotoran atau debu. Sesudah } \\
\text { dilakukan pembersihan } \\
\text { selang dimasukan kedalam } \\
\text { fitting solenoid valve. }\end{array}$ & 10 menit \\
\hline & & $\sqrt{ }$ & & $\begin{array}{l}\text { Pemeriksaan } \\
\text { kelistrikan pada } \\
\text { bagian solenoid valve }\end{array}$ & $\begin{array}{l}\text { Pemeriksaan menggunakan } \\
\text { avo meter. Membuka baud } \\
\text { pada bagian kepala } \\
\text { solenoid dan buka kepala } \\
\text { soleoid, cek aliran Y1,Y2,Y3 } \\
\text { dan Y4 dari solenoid } \\
\text { kebagian banana plug }\end{array}$ & 20 menit \\
\hline 3 & Silinder & $\sqrt{ }$ & & $\begin{array}{l}\text { Lakukan infeksi } \\
\text { kebocoran dan }\end{array}$ & $\begin{array}{l}\text { Tekan fitting lalu buka } \\
\text { seluruh selang bagian } \\
\text { silinder dan bersihkan }\end{array}$ & 10 menit \\
\hline 4 & $\begin{array}{l}\text { Air Filter } \\
\text { Regulator }\end{array}$ & $\sqrt{ }$ & & $\begin{array}{l}\text { Lakukan infeksi } \\
\text { kebocoran dan } \\
\text { melakukan } \\
\text { pergantian filter yang } \\
\text { berada didalam } \\
\text { filter unit. }\end{array}$ & $\begin{array}{l}\text { Membuka tabung filter } \\
\text { secara manual dan } \\
\text { melakukan pergantian, } \\
\text { pasangkan kembali filter } \\
\text { lalu kencangkan tabung } \\
\text { filter seperti semula }\end{array}$ & 20 menit \\
\hline
\end{tabular}




\section{KESIMPULAN}

Hasil sajian data dan pembahasan menunjukkan bahwa: 1) Alat peraga dibuat dengan model koper portable; 2) SOP dibuat sebagai panduan pengoperasian alat peraga elektropneumatik; 3) Perawatan alat peraga elektropneumatik menggunakan metode inspeksi, small repair dan medium repair (ISMO).

\section{REFERENSI}

[1] Sofyan, H., Efendi, A., \& Yogyakarta, U. N. (2017). Implementation of Teacherpreneurship on Teachers at Vocational High School, 102(August 2014), 229-236.

[2] Aizerman, M. A. (1968). Pneumatic and Hydraulic (Second). Rusia: Pergamon Press Ltd.

[3] Barber, A. (1997). Pneumatic Handbook. United States: Elsevier Science \& Technology Books.

[4] Budi Susilo. (2013). Rancang Bangun Simulator Pneumatik Nim : Budi Susilo Semarang.

[5] Priyonggo, P. (2013). Peningkatan Pemahaman Mata Kuliah Pneumatik Dan Hidrolik Dengan Bantuan Movie Clip Macromedia Flash Mx Multimedia dan Bentuk Kerangka Model Oleh:, (1), 74-84.

[6] Efendi, A., Nugraha, A., \& Baharta, R. (2019). Manufacturing of Electrical Dryer Machine for Food and Fruit Products Manufacturing of Electrical Dryer Machine for Food and Fruit Products. https://doi.org/10.1088/1757-899X/692/1/012006

[7] Prabowo, T. (2012). Simulasi Proses Pengepakan Botol Secara Otomatis dengan Kendali Elektro Pneumatik dan PLC. Semarang: Universitas Diponegoro.

[8] Bánesz, G. (2019). E-Learning in Electropneumatics Training, (July). https://doi.org/10.1007/978-3-030-11935-5

[9] Adhan Efendi, R. S. (2014). Perbaikan dan pemeliharaan mesin disc mill bongkol jagung, (1990), 97-104. 